\title{
Years with Hans Schmid
}

\author{
Hans-Jürgen Hansen*
}

\begin{abstract}
In commemoration of Hans Schmid, ${ }^{[1]}$ who would have celebrated his 91 st birthday on March 24 this year and as a note of thanks to my University on the occasion of the 175th anniversary.
\end{abstract}

Keywords: Institute of Organic Chemistry UZH · Schmid, H.

\section{First Steps}

With my intermediate diploma from the University of Marburg and with a scholarship for two terms at a foreign university in my pocket, I arrived for the first time in October 1962 in Zurich. But, in view of a possible place for my further studies in chemistry, I had climbed the broad stone stairs at Rämistrasse 76 up to the heavy wooden door with the carved inscription 'Chemisches Institut' at the top of the doorframe already in summer 1961 on the occasion of a holiday trip to the Lake Thun. ${ }^{[2]}$ The winter term 1962/63 opened a fantastic new world of chemistry for me.

The lectures and tutorials of Hans Schmid on 'Mechanisms of Organic Reactions' were impressive and when he came to the point to explain and exemplify general and specific acid catalysis, I became aware that mechanistic organic chemistry would be my field for later activities in research.

The grand seigneur under the professors was doubtlessly Klaus Clusius, and an extraordinary event in the wintertime 62/63 made his lecture on 'Thermodynamics' unforgettable. During December and January, a cold wind from the Alps, called the Bise, had been blowing with temperatures of $-10^{\circ} \mathrm{C}$ and below, with the result that at the

${ }^{*}$ Correspondence: Prof. Dr. H.-J. Hansen Institute of Organic Chemistry

University of Zurich

Winterthurerstrasse 190

$\mathrm{CH}-8057$ Zürich

Tel.: +4144635 4231

E-mail: H.-J.H@access.uzh.ch end of January the whole of Lake Zurich was completely frozen. Such a 'Seegfrörni' is an occasion that happens according to historical reports only every $30-40$ years, on average twice in a century. That morning, Clusius entered the classroom and said that he would talk on the conditions that have to be fulfilled for the whole lake to freeze over completely so that people could walk on the ice. ${ }^{[3]}$ In this exciting lecture we learned that a Bise of $-10^{\circ} \mathrm{C}$ or below has to blow for at least four weeks to overcome the heat capacity of the lake in a way that a stable cover of ice could be formed.

The lecture of PD André Dreiding on 'Synthetic Aspects of Organic Chemistry' was enriching, since we learned inter alia how to plan syntheses with 'Beilstein' as the literature source and we exercised this in all detail.

Lectures of Bartel Leendart van der Waerden (Mathematics for Natural Scientists), Robert Schwyzer (Selected Chapters of Biochemistry), PD Karl Bernauer (Chemistry of Small Ring Compounds), and Emil J. Walter (Introduction to the History of Natural Sciences) rounded off the exciting new world of chemistry that I had entered in Zurich

The most fruitful time for me started at the end of the winter term, when I read on a notice-board an advertisement from Hans Schmid saying that he was looking for a student who was interested to join, on payment, during the vacation time one of his groups for practical assistance in research. I went straightaway to the secretary of Hans Schmid to ask for a meeting. She knocked at the door of his office and a minute later I was asked by Hans Schmid to take place at a little round table in the corner of his office, which for all of us doing research in his group became the most important table in the 'Organischchemisches Institut der Universität Zürich' When he heard my interest in the advertised job, his first quick answer was: "Sorry, one of your colleagues, you should know him, Hans Jürgen Rosenkranz, has asked already for the job". Hans Schmid must have seen the look of disappointment and pure despair in my eyes, because he examined me a bit more because he knew me already from the tutorials in mechanistic chemistry, and when he heard that I had a full training as a technician, he unhesitatingly offered me a second place in his group. Thus, Hans Jürgen and I started as coworkers of Axel Habich, who was working on his $\mathrm{PhD}$ thesis on the socalled 'abnormal Claisen rearrangement', originally discovered by W. F. Lauer et al. in the thirties, and the mechanism of which was still in debate. ${ }^{[4]}$

It was my task to investigate the thermal Claisen rearrangement of trans-but-2-enyl 3,5-dimethylphenyl ether in N,N-diethylaniline. The established work-up with Claisen's alkali gave no problems. However, beside the expected ortho-allylated phenol, I isolated by column chromatography a slower moving mysterious second phenol. We had to await the result of the ${ }^{1} \mathrm{H}-\mathrm{NMR}$ analysis, which was in agreement with a symmetric trans-but-2-enyl phenol.[5] In other words, we had found the first example of a paraClaisen rearrangement of a butenyl phenyl ether with free ortho-positions. Hans Schmid was enthusiastic and to further establish this new finding, two of his co-workers, Richard Barner and János Borgulya, were incorporated in the work so that the first results could be published already in $1963,{ }^{[6]}$ at a time when I was already on the way to the University of Munich.

During the summer term 1963, I continued my studies in Zurich on organic chemistry with lectures of Max Viscontini (Vitamines), PD Wolfgang von Philipsborn (UV and IR spectroscopy), and Emil J. Walter (last part of his 'Introduction'). Again, there had been two events that impressed and formed me most. The lecture of André Dreiding on 'Organic Stereochemistry' gave 
a first definition and coherent picture of the field of stereochemistry, supported by the 'Dreiding Models', which he introduced to us as an imperative 3D companion for chemistry in three-dimensional space, and, most exciting, students who had registered for his lecture, could buy the models at Büchi/ Flawil with a price reduction of $15 \%$. ${ }^{[7]}$ I attended the "Tutorials in Organic Chemistry for Advanced Students", given by Hans Schmid late afternoon every Monday. He was an excellent, but also merciless, teacher, so that there were two categories of students. For the first category, to which I belonged, admiration was greater than fear and the second category had just the reverse feeling. As a result E.S. Gould's book on 'Mechanism and Structure in Organic Chemistry' ${ }^{[8]}$ and E. L. Eliel's 'Stereochemistry of Carbon Compounds' became my daily reading. And there was the practical course for advanced students under the supervision of PD Conrad $\mathrm{H}$. Eugster (CHE). Here, we learned how to do catalytic hydrogenation in a closed apparatus with two equal flasks connected by a u-tube, filled with dibutyl phthalate to compensate the solvent pressure, and equipped with a gas burette, to determine the mole-equivalents of hydrogen consumed by a weighed amount of compound. More exciting was the introduction to thin-layer chromatography (TLC), since first we had to learn how to cover the glass plates with an equally thin layer of silica gel. The highlight after this training was the TLC analysis of a tiny amount of raw opium that CHE cut with his knife from a black smoked lump of opium, which afterwards was stored again in a huge old safe from Alfred Werner's time. And we became acquainted with a number of spray reagents for the development of the plates, specifically Schlittler's reagent (for alkaloids) and phosphomolybdic acid (for phenols and their derivatives). The last part of the course was dedicated to small research topics, different for every participant. CHE gave me the task to investigate the resolution of racemic diheptyl malate, which I had first to synthesize, via its urea inclusion complex. First I had to train myself with the formation of known complexes of long-chain hydrocarbons (from n-octane upward), which are built by slow addition of the hydrocarbon to a saturated solution of urea in methanol. By the end of the semester, I was able to induce the hexagonal crystallization of urea also with the malic acid diester. But no time was left for further investigations and the summer vacation time started, which altered all my planes for the continuation of my studies in Marburg.[9]

\section{Munich Intermezzo}

At the beginning of October 1963 I was back in Munich, where I worked for a short time in the group of Rolf Huisgen to learn more about 1,3-dipolar cycloaddition reactions and afterwards in the group of Klaus Hafner to become familiar with fulvene and azulene chemistry, animated by review articles which had been published by both in Angew. Chem. ${ }^{[10]}$ However, I had decided to do my diploma thesis in inorganic chemistry in the group of Egon Wiberg, because Axel Habich had indicated in a chat that Hans Schmid would be interested that I joined his group again after I had finished my diploma examinations in Munich. My idea was to study boron trichloride catalyzed aromatic Claisen rearrangements and their transition state geometry. Egon Wiberg and his school was the address in boron chemistry at that time in Germany. Therefore, I tried to learn as much as I could on boron chemistry and shifted my studies to inorganic chemistry as the main branch, ${ }^{[11]}$ but was also attending the famous 'Seminar of Organic Chemistry' of Huisgen and had registered for lectures in biochemistry, read by Feodor Lynen, and for physical chemistry, read by Georg-Maria Schwab. ${ }^{[12]}$

In the summer term 1964, I started my diploma work in the group of Wiberg under the supervision of Dr. Peter Paetzold, who was on the way to his habilitation (1966). I got the task to synthesize dimethyl boron azide, a new compound, the structure of which was unknown (bent $C_{\mathrm{s}}$ symmetry or linear $C_{2 \mathrm{v}}$ symmetry?). The final full vibrational analysis that we made was only compatible with $C_{\mathrm{s}}$ symmetry. ${ }^{[13]}$

Early springtime 1965 I received an official letter from Hans Schmid, in which he offered me a position as SNF research assistant in his group. I was happy and agreed to start in May 1965. After two rich and intense Fasching and Oktoberfest seasons and as a diploma chemist I left Munich on May 5, on course for Zurich.

\section{Back in Zurich}

When I re-entered the 'mechanistic group' I met two wonderful colleagues, Georg Fràter and Janos Zsindely, who were working already for a while on Claisen and related rearrangements. We three were hard working and became good friends, also outside the university. My first research place was in Lab 17,[14] close to the bench of Hans Jürgen Rosenkranz, who had started his PhD work on the synthesis of tuboflavine and analogues already end of $1963^{[15]}$ and where Janos had his bench. Georg, Janos, and I, we formed a sort of mechanistic troika, with new ideas every day and endless discussions, since the Woodward-Hoffmann rules had been published just that summer in J. Amer. Chem. Soc. Fortunately, Hans Schmid gave us the necessary freedom to realize our own ideas as long as these ideas were brought to success. Otherwise, he could become very angry.

Georg had almost finished already an investigation on the thermal reversible cis/ trans isomerization of 2-(but-2-enyl)-phenols via the abnormal Claisen rearrangement, which after Woodward and Hoffmann could be characterized as [1,5]-homosigmatropic H-shifts. ${ }^{[16]}$ Georg and I worked on the transition state of the aromatic Claisen rearrangement under different aspects. Georg followed the stereochemical course of the combined ortho/para rearrangement of cisand trans-configured but-2-enyl 2,6- and 3,5-dialkylphenyl ethers and I worked on the thermal rearrangement of (1-methylallyl) 2-R-phenyl ether ( $\mathrm{R}=\mathrm{H}, \mathrm{Me}, \mathrm{Et}$, i-Pr, $t$-Bu). Both approaches indicated clearly that the rearrangements followed mainly chair-like transition states. ${ }^{[17]}$ Georg was interested in the chemistry of allyl phenyl ethers and the corresponding phenols. I made a complete analysis of all Cope rearrangements, including those of bi- and tricyclic compounds with a structurally forced boat-like transition state and of Claisen rearrangements in the aliphatic series. As a result Georg discovered the photochemical ring closure of ortho-allyl phenols to cumaranes and chromanes ${ }^{[18]}$ (independently found by W.D. Horspool in England at almost the same time) and a bit later the very first 'super-Claisen' rearrangement of penta-2,4-dienyl phenyl ether with the migration of the pentadienyl residue across the benzene part just in para-position. ${ }^{[19]}$ It was the first fully characterized [5s,5s]-sigmatropic process. I proposed to Hans Schmid to apply a 'reverted' Doering-Roth system for the exact determination of the transition state geometry of the thermal rearrangements of allyl vinyl ethers. ${ }^{[20]}$ Since I was completely occupied by a full characterization of the acid-catalyzed dienol-benzene rearrangement of simple allyl-cyclohexadienols (see below), the task of synthesizing all four stereoisomers of but-2-enyl prop-1-enyl ether and their thermal rearrangement in heptane became the topic of the diploma thesis of Piero R. Vittorelli. In 1968, we could report on preliminary results, ${ }^{[21]}$ which we later enriched and secured by the corresponding gas-phase rearrangements and their kinetics.[22]

Janos was the undoubted expert in [3,3]sigmatropic rearrangements of Cope and Claisen systems with a propargyl moiety.[23] It was known that the thermal rearrangement of propargyl phenyl ethers led to $2 \mathrm{H}$ chromenes, but the mechanism of chromene formation was in debate. Janos showed that chromene formation was also observed on thermal rearrangement of propargyl paracyclohexadienones. These findings allowed the conclusion that 2-allenylphenols are the crucial intermediates, which are transformed by $[1,5]-\mathrm{H}$ shifts in $\omega$-vinyl-quinomethanes, followed by thermal electrocyclization of the 
latter to $2 \mathrm{H}$-chromenes. Indeed, independently prepared 2-allenylphenol rearranged on heating smoothly into $2 \mathrm{H}$-chromene and the rearrangement of the O-deuterated phenol was about 10 times slower, showing that the $\mathrm{H}$-shift was the rate determining step of the rearrangement of the 2-allenylphenol. However, more thrilling were Janos' experiments with propargyl 2,6-dimethylphenyl ether and higher alkylated forms of it. $\mathrm{He}$ isolated on heating of the basic system a camphor-like smelling compound with unusual spectroscopic properties, which gave reasons for long discussion on the blackboard. A number of spectroscopic data were in agreement with the presence of a strained cyclopropane moiety. The final answer gave the observation of the ${ }^{13} \mathrm{C}$ side bands of one of the $\mathrm{H}$-atoms, presumed to be sitting at a strained cyclopropane ring. The observed ${ }^{1} \mathrm{~J}\left(\mathrm{H},{ }^{13} \mathrm{C}\right)$ of $c a .174 \mathrm{~Hz}$ could only be explained indeed with the presence of a cyclopropane ring. The mechanistic picture was complete: The ether showed a normal thermal rearrangement to the corresponding 6-allenyl-2,6-dimethylcyclohexa-2,4-dien1-one, which then underwent an intramolecular Diels-Alder reaction with its diene system and the inner allenyl bond. ${ }^{[24]}$ These new strained tricyclic compounds showed a variety of different thermal and acid-catalyzed reactions. ${ }^{[25]}$

Benno Sutter had reported in his $\mathrm{PhD}$ thesis that the two stereoisomers of 4-allyl4-methyl-cyclohexa-2,5-dien-1-ol gave on treatment with $\mathrm{TsOH}$ in $\mathrm{Et}_{2} \mathrm{O}$ mainly a mixture of 2- and 4-allyltoluene. ${ }^{[26]}$ The formation of 3-allyltoluene could be not excluded, but when formed then in the range of $5 \%$ or below. By labeling experiments with ${ }^{14} \mathrm{C}$, Sutter could demonstrate that 2-allyltoluene was formed with retention and 4-allyltoluene with inversion of the $\mathrm{C}$-atom array of the allyl group. Therefore, he proposed a possible tropylium ion-like transition state $\mathrm{F}$ (Fig. 1) for the formation of the latter. This idea was exciting in view of the WoodwardHoffmann rules, since the proposed transition state structure $\mathrm{F}$ characterized in the terminology of Woodward and Hoffmann a [3s,4s]-sigmatropic process. Hans Schmid asked me to complete and finish the research work of Sutter, which I did with full success due to a new type of glass-capillary columns, developed by Kurt Grob, professor at the Kantonsschule Rämibühl and lecturer at our institute, which allowed the separation of all three allyltoluenes and the demonstration that 3 -allyltoluene results indeed from a [3s,3s]rearrangement. ${ }^{[27]}$ Later on, we proved with P. Vittorelli, Jasna Peter-Katalinic, and Gabriele Mukherjee-Müller the generality of $[3 \mathrm{~s}, 4 \mathrm{~s}]$-sigmatropic rearrangements in cyclic allyl cations. ${ }^{[28]}$ Moreover, we found [3s,4s]migrations of allyl moieties also in boron trichloride catalyzed rearrangements of allyl cyclohexadienones and their corresponding ethers, ${ }^{[29]}$ and it was shown by Ulrich $\mathrm{R}$. Widmer that the 'magic inducer' of such rearrangements in allyl ortho- and para-cyclohexadienones was trifluoroacetic anhydride, if it was completely free of trifluoroacetic acid. ${ }^{[30]}$ On the other hand, propargyl cyclohexadienones showed [3,4]-rearrangements with the propargyl group already by treatment with acetic anhydride/ $\mathrm{H}_{2} \mathrm{SO}_{4} \cdot{ }^{[31]}$ The ease to involve propargyl substituents in $[3,4]$-processes had already been demonstrated by Heinz Heimgartner in his $\mathrm{PhD}$ thesis on the acid-catalyzed dienol-benzene rearrangement of propargyl ortho- and paracyclohexadienoles. ${ }^{[32]}$

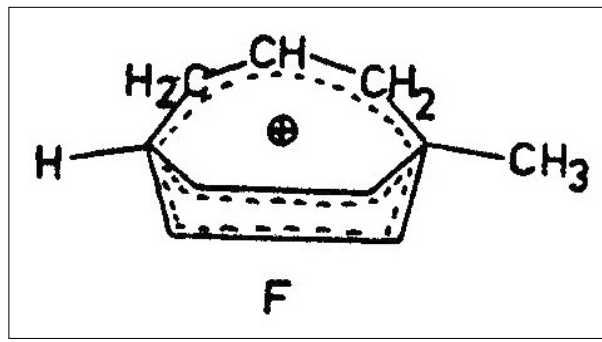

Fig. 1. A possible tropylium ion-like transition state F, proposed by Benno Sutter

One day at end of October 1968 Hans Schmid came in Lab 4 and asked me if I had looked at my mail at home. No, I had not. Have a look this evening or tomorrow, said Hans Schmid and left the lab. Indeed, later at home I found a letter from the 'Erziehungsdirektion des Kantons Zürich' that I had been appointed 'Oberassistent' from 1st November 1968 at the Institute of Organic Chemistry. Hans Schmid had not said a single word to me in advance, but I was happy with his decision.

The first congress on 'Orbital Symmetry Correlations in Organic Chemistry' took place in Cambridge (January 7-9, 1969) and Hans Schmid had decided that I should go. I wanted to present my latest results on $[1,5]$-H-shifts in 2-vinyl- and 2-(prop-1enyl)phenols, which I had investigated from the beginning of 1968. And first results had shown that 1-cis-configured 2-(penta-1,3-dienyl)phenols underwent smoothly $[1,7]-\mathrm{H}-$ shifts under cis/trans-isomerization of the outer $\mathrm{C}=\mathrm{C}$ bond and formation of 2 -ethyl- $2 \mathrm{H}$ chromene already at $121^{\circ} \mathrm{C}$, whereas the 1 trans-configured pentadienylphenols had to be heated at $190^{\circ} \mathrm{C}$ to form the chromene. [33] Hans Schmid agreed. The auditorium was almost completely filled, when I begun my 20 minutes speech. Woodward was sitting together with Huisgen in the first row. When I introduced the part of the thermal behavior of the pentadienylphenols, I started with saying: If we look through WoodwardHoffmann glasses at these reactions.... the whole auditorium was slightly smiling and especially Woodward. In other words, everything went well. Again in Zurich, I had to report Hans Schmid in detail on the congress and aromatic sigmatropic $\mathrm{H}$-shifts became for the next years one of our main topics in mechanistic research (see [34] and especially the work with Heinz Heimgartner ${ }^{[35]}$ ).

Before I close this section on ground state chemistry, I go back to a last example of our research on the transition state geometry of a para $\rightarrow$ ortho-Claisen rearrangement, which also can be regarded, of course, as a Cope rearrangement, to exemplify the specific motivation that Hans Schmid induced in all of us working with him. One day in early 1969 Hans Schmid came in my lab complaining that he had no idea what he should talk about in a lecture at a conference in five weeks. I made several proposals, but he was not really satisfied. So, I said, let me think about it. I had already something in mind, but I wanted to discuss my idea and its realization within four weeks with Janos. The idea was alkylate oestradiol with 2-butenyl chloride, isolate the expected 10 $\beta$-(but-2-enyl)cyclohexadienone, purify it by crystallization to get the pure trans-butenyl form and then perform the thermal rearrangement perhaps to a mixture of the 2- and 4-(1-methylallyl)oestradiols. The next steps were separation of the two regioisomers, hydrogenation of the external $\mathrm{C}=\mathrm{C}$ bond, followed by ozonolysis, isolation of the $\alpha$-methylbutyric acid, and finally determination of the optical rotation of the two acids. The stereochemical analysis predicted the formation of the $(S)$ enantiomer from the 2-substituted oestradiol and the $(R)$-enantiomer from the 4-form. Janos and I discussed this course of action in detail. We were convinced that we could manage the labor in four weeks when Alfred Wunderli, who had just started his PhD work in our group, joined the project. We proposed the whole project to Hans Schmid. He was skeptical, but finally he agreed to at least try it. Janos was responsible for the synthesis of the dienone in pure trans-form, A. Wunderli performed model experiments with but-2-enyl 5,6,7,8-tetra-hydro-2-naphthyl ether and its corresponding 10-(but-2-enyl)dienone and their thermal rearrangement, and I was responsible for the separation of the 2- and 4-isomers after rearrangement, their hydrogenation, and ozonolysis. Indeed, we succeeded; after four weeks I could measure the optical rotation of the two acids with a classical Zeiss polarimeter. Hans Schmid did not believe me, therefore, he followed me into the small completely dark polarimeter room. I made ten measurements, then Hans Schmid. We looked at our average values and, indeed, they were almost the same within the limits of error, telling us that at least $94 \%$ had rearranged via a chair-like transition state and not more than $6 \%$ via a boot-like form. ${ }^{[36]}$ Hans Schmid was happy, and so were we.

Most of the papers with Hans Schmid were discussed and formulated at the little round table in his office, which is seen on a snapshot from 1972 (Fig. 2). On the black- 
board behind us one can recognize vaguely allene structures, because we were preparing the manuscript on investigations of the mechanism of the Saucy-Marbet rearrangement, ${ }^{[37]}$ which had been performed by Horst Schlossarczyk in his $\mathrm{PhD}$ work ${ }^{[38]}$ and six years later by Willy Sieber in his diploma work. ${ }^{[39]}$

Since $1968 \mathrm{I}$ had also been involved in the photochemical research of Hans Schmid's group. With Linus Ulrich, Heinz, and W. Sieber we studied on my suggestion the photochemical behavior of 1,2-dihydronaphthalenes carrying alkyl substituents at $\mathrm{C}(1)$ and/ or $\mathrm{C}(2)$ in great detail.[40] The photochemical step was the electrocyclic ring opening of these benzocyclohexadienes, followed by thermal $[1,7]-\mathrm{H}$-shifts in the formed $\omega$-alkenyl-quinodimethanes, so that 1,2-dialkenyl- or 1-alkyl-2-pentadienylbenzenes were formed, which reacted photochemically to benzobicyclo[3.1.0]hex-2-enes. The $[1,7]-\mathrm{H}$-shifts could be completely suppressed, when the irradiations of the 1,2-dihydronaphthalenes were performed at -100 ${ }^{\circ} \mathrm{C}$ and new photoproducts derived from excitation of the $\omega$-vinyl-quinodimethanes appeared. In this way, we observed the formation of 1-alkyl-2-allenyl- and 1-alkenyl2-allylbenzenes and, in addition, again benzobicyclo[3.1.0]hex-2-enes with a different substituent pattern. ${ }^{[41]}$ The observed product types had all been found earlier already by Havinga et al. on irradiation of vitamin $\mathrm{D}_{3}$.

Most important had been the finding in Hans Schmid's group that indazoles could photochemically be isomerized to benzimidazols, benzisoxazole to benzoxazoles, and pyrazoles to imidazoles ( $c f$. [1]). We studied with Emanouil Georgarakis and Thomas Doppler these photo-rearrangements in acidic media and found that under these conditions the protonated heterocycles underwent a photo-solvolysis to the corresponding nitrenium or oxenium ions, which picked up a nucleophile in para- and orthoposition to the $\mathrm{N}$ - or $\mathrm{O}$-atom carrying the positive charge. ${ }^{[42,43]}$

However, the most exciting photoreaction, we found, was the photochemical ring opening of 3-phenyl-2H-azirines to nitrile ylides, which then could be trapped by 1,3-dipolar cycloaddition reactions with reactive $\mathrm{C}=\mathrm{C}$ or $\mathrm{C}=\mathrm{X}$ bonds. Our first publication on this topic had appeared in 1972, [44] however, Hans Schmid had already lectured on it in 1969 at the 'Deuxième Congrès International de Chimie Hétérocyclique'. Nevertheless, A. Padwa and J. Smolanoff ${ }^{[4]}$ reported at the same time on the photochemistry of $2 \mathrm{H}$-azirines. In other word, we were proud of our findings, but not alone.

I will close this retrospective of an extremely exciting period under Hans Schmid at the old institute at Rämistrasse 76 with two spectral presentations (Fig. 3) showing the photochemical transformation of triphenyl-2H-azirine into the corresponding nitrile

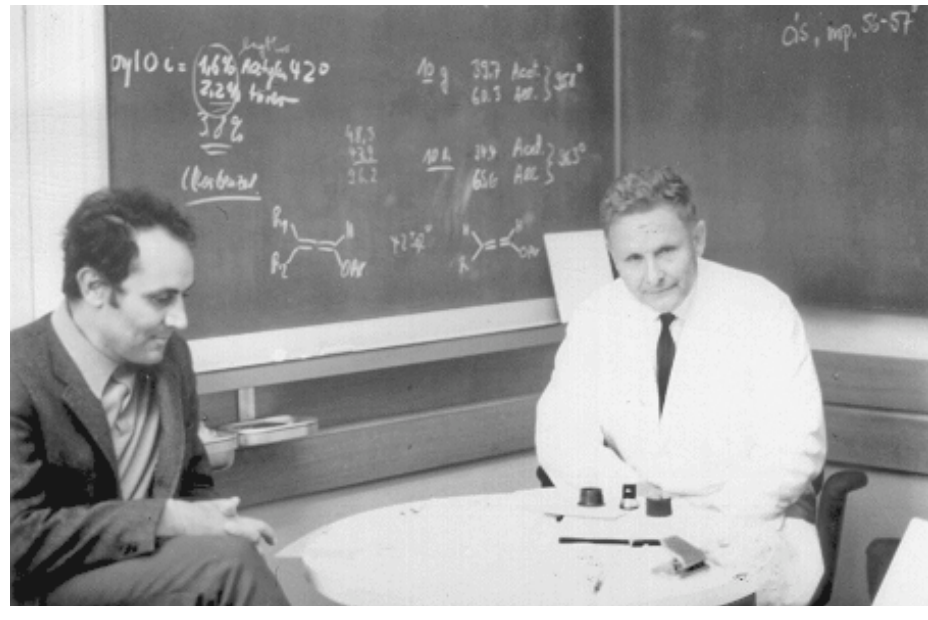

Fig. 2. Hans Schmid and the author in Schmid's office, 1972

ylide and the reformation of the $2 \mathrm{H}$-azirine on irradiation into the nitrile ylide band.[46] This time, we were the first.

Received: January 28, 2008
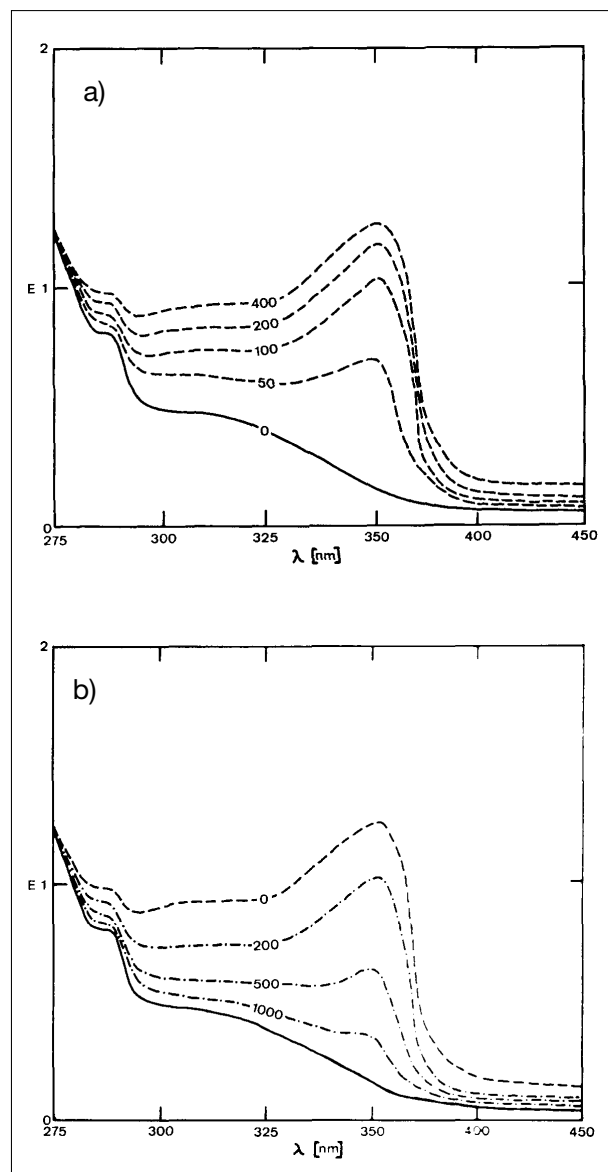

Fig. 3. The photochemical transformation of triphenyl-2H-azirine into the corresponding nitrile ylide (a) and the reformation of the $2 \mathrm{H}$-azirine on irradiation into the nitrile ylide band (b)

[1] H.-J.Hansen, M. Hesse, W. von Philipsborn, Helv. Chim. Acta 1978, 61, 1.

[2] After mounting a further staircase in the porch, I entered the building through a swing door on the first floor. This summer day at noon almost all offices were empty and only on the second floor, after going past the bust of Haruthiun Abeljanz on a column, I found at the end of the corridor an office with some tinkering around inside. When I knocked at the door a calm female voice said: Please, come in. I entered the office of Fräulein Lieselotte Guyer, secretary of Prof. Ernst Schumacher, at that time, Director of the Institute of Inorganic Chemistry. Fräulein Guyer answered in a wonderfully polite and lady-like manner all my burning administrative questions on doing studies in chemistry at the University of Zurich. After this extraordinary 25 minute encounter, it was absolutely clear for me that I would do the envisaged two terms at a foreign university at Zurich, and the idea of being in the near future in Zurich helped me fabulously in passing the examinations of the intermediate diploma at Marburg in the summer term 1962.

[3] The last one had been in the winter 1929. Indeed, at the end of January, Günter Mattern, who did later on his $\mathrm{PhD}$ thesis in the group of Max Viscontini, came to Kilchberg, where I had a room at that time, to fetch me for a walk to Bellevue across the lake and for a later dinner at the restaurant Ostschweizer Weinstuben (today the Heugümper); an exceptional day for both of us.

[4] $\mathrm{PhD}$ thesis of A. Habich, University of Zurich, 1963 as well as A. Habich, R. Barner, R.M. Roberts, Helv. Chim. Acta 1962, 45, 1943 and A. Habich, R. Barner, W. von Philipsborn, Helv. Chim. Acta 1965, 48, 1297. See also H.-J. Hansen, in 'Mechanisms of Molecular Migrations', Ed. B. S. Thyagarajan, Wiley-Interscience, New York, 1971, 3rd vol., p. 177-236.

[5] Dr. Rosanna Modelli from Italy, who had been the first postdoc of Wolfgang von Philipsborn in 1962/63, recorded the ${ }^{1} \mathrm{H}-\mathrm{NMR}$ spectrum on the Varian A 60 instrument that the institute had acquired in 1961 as the first routine machine and the first instrument of this type at all in Switzerland.

[6] J. Borgulya, H.-J. Hansen, R. Barner, H. Schmid, Helv. Chim. Acta 1963, 46, 2444.

[7] Of course, I bought the smallest available box with models. My budget did not allow more. However, these models, enriched by some specific structure elements, are still within reach at my desk at home, since $3 \mathrm{D}$ feeling is not the same as 3D viewing on a computer screen. 
[8] After the winter term 1961/62 at Marburg, I attended a course on ion exchange chromatography, ran by Dr. Bruno Sansoni, who was working at that time on his habilitation. Since we found a new way of metal complex formation (Angew. Chem. 1962, 74, 466), I won Jack Hine's 'Physical Organic Chemistry' as a prize for excellence in bench work. Moreover, another influential work for my understanding of organic chemistry was Heinz A. Staab's 'Einführung in die theoretische organische Chemie'. Both books were in my luggage to Zurich.

[9] My original idea was to return to Marburg and work with Hans Musso. However, in the course of holidays in the Zillertal in Austria, my fiancée and I made an excursion to Munich. The chemical institutes of the university were in walking distance to the main railway station of Munich, so, there were no obstacles to having a look at the institutes before starting our cultural program (Lehnbach-Haus, Alte Pinakothek, etc.). Klaus Hafner, whom I knew from Marburg, was in his office. He welcomed me but said at the beginning of our short talk: "Look, if you want to register for the winter term, I need your documents and certificates by tomorrow morning. It is the last day for registration at the chancellery of the university". I interpreted this circumstances as a real challenge for me, and I managed to get my papers next morning by express delivery from my landlady in Kilchberg. Everything went well and within a day and a half I became a diploma student of the University of Munich. Moreover, I also found lodgings in Schwabing.

[10] With the intermediate diploma in hands, students could enter as junior members (cand. chem.) of the 'Gesellschaft Deutscher Chemiker' and subscribe for a very low price to Angew. Chem. I have received the journal since 1962 . Volume 75 of the journal appeared in 1963. It contained inter alia milestone articles of Huisgen on 1,3-dipolar cycloaddition reactions, of Hafner on fulvenes and azulenes, and of Doering and Roth on the geometry of the transition state of Cope rearrangement.

[11] Heinrich Nöth, at that time PD, then Professor of inorganic chemistry in Marburg, and finally successor of Egon Wiberg in Munich, gave the lecture on 'Introduction to Boron Chemistry' in Munich.

[12] Schwab loved Ulich's approximate equations and taught them in extenso in his lecture. I tried to understand and learn them for the diploma examination in physical chemistry. So, I was well prepared when I entered his office on the morning of the examination. However, his first question was: Explain to me the Menschutkin reaction. All my complex knowledge on thermodynamics broke down at this moment, I was confused and I needed some minutes to recover and remember Schmid, Gould, Hine, Staab to be in line with the question, so that I could answer fluently and extensively. He put forward only one further question in physical chemistry, I suppose as a spot check. My answer seemed to satisfy him, I left his office after two thirds of the official time of examination (30 $\mathrm{min})$, and I was relieved and happy.

[13] P. I. Paetzold, H.-J. Hansen, Z. anorg. allg. Chem. 1966, 345, 79.

[14] When Axel Habich left the institute and the famous Lab 4 to join the group of Nobel prize winner Severo Ochoa in New York (University School of Medicine), Hans Schmid offered me the chance to move to $\mathrm{Lab} 4$. It was the former private laboratory of Paul Karrer, who had his office just above Lab 4 and a spiral staircase connected his office with Lab. 4. Later on, the staircase was removed and replaced by a modern fume-cupboard. In Lab. 4 awaited me also a technician, Gerhard Stucki. Later, Stanislav Chaloupka (SC) from former Czechoslovakia occupied the position. $\mathrm{He}$ was an excellent technician and a wonderful faithful soul. When I left the University of Zurich at end of March 1973, to continue my career at the University of Friboug ( $c f$. [43], lit. in parentheses), Heinz Heimgartner took over my position and SC became his coworker. After the death of Hans Schmid (19.12.1976) Heinz could keep SC for three years, which was a great help for Heinz, especially when the great move from Rämistrasse 76 to the Irchel, Winterthurerstrasse 190 took place. At the end of the three years, SC found an excellent position in the group of Luigi Venanzi at the ETH

[15] H. J. Rosenkranz, G. Botyos, H. Schmid, Liebigs Ann. Chem. 1966, 691, 159.

[16] G. Fràter, Ph.D. thesis, University of Zurich, 1967; G. Fràter, H. Schmid, Helv Chim. Acta 1966, 49, 1957; see also H.-J. Hansen, Helv. Chim. Acta 1977, 60, 2007.

[17] G. Fràter, A. Habich, H.-J. Hansen, H Schmid, Helv. Chim. Acta 1969, 52, 355.

[18] G. Fràter, H. Schmid, Helv. Chim. Acta 1967, 50, 255

[19] G. Fràter, H. Schmid, Helv. Chim. Acta 1968, 51, 190 and Helv. Chim. Acta 1970. $53,269$.

[20] H.-J. Hansen, PhD thesis, University of Zurich, 1968.

[21] P. Vittorelli, T. Winkler, H.-J. Hansen, H. Schmid, Helv. Chim. Acta 1968, 51, 1457.

[22] P. Vittorelli, H.-J. Hansen, H. Schmid, Helv Chim. Acta 1975, 58, 1293.

[23] J. Zsindely, $\mathrm{PhD}$ thesis, University of Zurich, 1971.

[24] J. Zsindely, H. Schmid, Helv. Chim. Acto 1968, 51, 1510.

[25] J. Peter-Katalinic, J. Zsindely, H. Schmid, Helv. Chim. Acta 1973, 56, 2796 and Helv Chim. Acta 1974, 57, 223.

[26] B. Sutter, $\mathrm{PhD}$ thesis, University of Zurich, 1964.

[27] H.-J. Hansen, B. Sutter, H. Schmid, Helv Chim. Acta 1968, 51, 828. The publication formed the main part of my $\mathrm{PhD}$ thesis Therefore, Hans Schmid asked me to prepare a draft for the publication. I did and waited expectantly for his assessment. He invited me to his home at Greifensee. There he made a critical analysis of my writing and showed me how to do it to the highest possible scientific standards, which meant that he changed almost every second sentence in the theoretical part. He explained patiently the reason for his corrections and I learned all I needed for future publications - with the Lake of Greifensee close to his house and the panorama of the Alps in the background.

[28] H.-J. Hansen, P. Vittorelli, J. PeterKatalinic, G. Mukherjee-Müller, Helv. Chim. Acta 1975, 58, 1379.

[29] R. Barner, J. Borgulya, R. Madeja, P. Fahrni, H.-J. Hansen, H. Schmid, Helv. Chim. Acta 1973, 56, 14.

[30] U. Widmer, J. Zsindely, H.-J. Hansen, H. Schmid, Helv. Chim. Acta 1973, 56, 75

[31] U. Widmer, H.-J. Hansen, H. Schmid, Helv. Chim. Acta 1973, 56, 1895.

[32] H. Heimgartner, J. Zsindely, H.-J. Schmid, Helv. Chim. Acta 1972, 55, 1113.

[33] R. Hug, H.-J. Hansen, H. Schmid, Chimia 1969, 23, 108 and Helv. Chim. Acta 1972, $55,1828$.

[34] H.-J. Hansen, H. Schmid, Chimia 1970, 24 89.

[35] H. Heimgartner, H.-J. Hansen, H. Schmid, Helv. Chim. Acta 1972, 55, 1385; $\mathrm{H}$ Heimgartner, J. Zsindely, H.-J. Hansen, H. Schmid, Helv. Chim. Acta 1973, 56, 2924.

[36] A. Wunderli, J. Zsindely, H.-J. Hansen, H. Schmid, Helv. Chim. Acta 1973, 56, 989.

[37] H. Schlossarczyk, W. Sieber, M. Hesse, H.-J. Hansen, H. Schmid, Helv. Chim. Acta 1973, 56, 875.

[38] H. Schlossarczyk, PhD thesis, University of Zurich, 1964

[39] The years 1971-1973 were heavily loaded with work. H. Schmid and I were also working on Sunday mornings. Some day my wife was fed up with the situation and shouted at me: "You, you and Prof. Schmid are ill, really ill! You are suffering from galloping sigmatropy!". Axel Habich called all this the Big Allyl.

[40] L. Ulrich, H.-J. Hansen, H. Schmid, Helv. Chim. Acta 1970, 53, 1323; H. Heimgartner, L. Ulrich, H.-J. Hansen, H. Schmid, Helv. Chim. Acta 1971, 54, 2313.

[41] W. Sieber, H. Heimgartner, H.-J. Hansen, H. Schmid, Helv. Chim. Acta 1972, 55 , 3005.

[42] M. Georgarakis, T. Doppler, M. Märky, H.-J. Hansen, H. Schmid, Helv. Chim. Acta 1971, 54, 2916; E. Georgarakis, H. Schmid, H.-J. Hansen, Helv. Chim. Acta 1979, 62, 234.

[43] T. Doppler, H. Schmid, H.-J. Hansen, Helv. Chim. Acta 1979, 62, 271, 304, and 314 . The photochemical bond cleavage of anthraniles in strong acidic media (conc. $\mathrm{HCl}, \mathrm{HBr}$ ) was independently found by Edgardo Giovanninis group in Fribourg (cf. H.-J. Hansen, Chimia 2004, 58, 903).

[44] H. Giezendanner, $\mathrm{PhD}$ thesis, University of Zurich, 1972; H. Giezendanner, M. Märky, B. Jackson, H.-J. Hansen, Helv. Chim. Acta 1972, 55, 745 .

[45] A. Padwa, J. Smolanoff, J. Amer. Chem. Soc. 1971, 93, 548.

[46] W. Sieber, P. Gilgen, S. Chaloupka, H.-J. Hansen, H. Schmid, Helv. Chim. Acta 1973, 56, 1679; see also H.-J. Hansen, H. Heimgartner, in 'I,3-Dipolar Cycloaddition Chemistry', Ed. A. Padwa, John Wiley \& Sons, New York, 1984, p. 177-290 for further developments. 